\title{
Tumor Necrosis Factor $\alpha$ But Not Interleukin $1 \beta$ Mediates Neuroprotection in Response to Acute Nitric Oxide Excitotoxicity
}

\author{
Nicolas P. Turrin and Serge Rivest \\ Laboratory of Molecular Endocrinology, Centre Hospitalier de l'Université Laval Research Center, and Department of Anatomy and Physiology, Laval \\ University, Sainte-Foy, Québec, Canada G1V 4G2
}

\begin{abstract}
Neurodegenerative processes in the brain are accompanied by activation of innate immunity, which involves the release of proinflammatory cytokines by microglia and infiltrating macrophages. The beneficial or detrimental roles of these cytokines, including interleukin $1 \beta$ (IL-1 $\beta$ ) and tumor necrosis factor $\alpha$ (TNF- $\alpha$ ), remain to be clarified. These cytokines have numerous overlapping activities that make it difficult to interpret data generated by mice that have a mutation in the gene encoding either TNF- $\alpha$ or IL-1 $\beta$. To remediate the problem, we generated a mouse that bears a mutation in both genes and exposed them to an acute neurotoxic insult. Intracerebral infusion with the nitric oxide donor sodium nitroprusside (SNP) caused neurodegeneration and demyelination that were markedly increased in the brain of TNF- $\alpha$ - and IL-1 $\beta /$ TNF- $\alpha$-deficient mice compared with IL-1 $\beta$-deficient and wild-type mice. Surprisingly, TNF and double mutants exhibited an early ( $6 \mathrm{~h}$ after SNP injections) blunted microglial activation followed by an exaggerated response later on ( $4 \mathrm{~d}$ later). No differences were found in the brain of the IL- $1 \beta$ knock-out and wild-type groups. This suggests a crucial role for TNF- $\alpha$ in mediating microglial reactivity to acute injury. An immediate response clearly helps eliminate cell debris, restrict subsequent damages, and restore homeostasis. These findings may have direct implications for the use anti-inflammatory drugs in acute neurodegenerative and demyelinating disorders.
\end{abstract}

Key words: cytokines; inflammation; innate immunity; microglia; neurodegeneration; NF- $\kappa \mathrm{B}$; nitric oxide; TNF- $\alpha$; mutant mice

\section{Introduction}

It is now established that the CNS is able to mount an immune response to most threatening stimuli. Microglial cells are at the core of this response, because they are capable of phagocytosis and can act as antigen-presenting cells. Furthermore, microglia can release soluble factors, such as cytokines, heat shock proteins, and acute phase proteins, which propagate and perpetuate the cerebral immune response. The role of microglia and proinflammatory cytokines in the CNS has now been characterized in models of brain insults, ranging from bacterial and viral infections (Boivin et al., 2002; Laflamme et al., 2003; Soulet and Rivest, 2003; Soucy et al., 2005) to axonal injury (Perrin et al., 2005), seizures (Turrin and Rivest, 2004), and neurodegenerative disorders (Nguyen et al., 2004). Although inflammation should be adaptive, the release of proinflammatory cytokines has often been associated with detrimental consequences to neurons and myelin. For example, tumor necrosis factor $\alpha$ (TNF- $\alpha$ ) is thought

\footnotetext{
Received July 28, 2005; accepted Nov. 6, 2005.

This work was supported by The Canadian Institutes in Health Research. N.P.T. is the recipient of a postdoctoral fellowship from the Multiple Sclerosis Society of Canada. S.R. holds a Canadian Research Chair in Neuroimmunology. We are grateful to Dr. P. Gray (Genentech, South San Francisco, (A) for the plasmid containing the mouse IL-1 $\beta$ CDNA, Dr. S. C. Williams (Texas Tech, Lubbock, TX) for the plasmid containing the MCP-1 CDNA, and N. Laflamme for her technical support in generating the other CDNA probes.

Correspondence should be addressed to Dr. Serge Rivest at the above address. E-mail: Serge.Rivest@ crchul.ulaval.ca.

DOI:10.1523/JNEUROSCI.4032-05.2006

Copyright $\odot 2006$ Society for Neuroscience $\quad 0270-6474 / 06 / 260143-09 \$ 15.00 / 0$
}

to enhance apoptotic processes through its action on its type 1 receptor (TNFR1) in models of acute (ischemia, excitotoxicity) and chronic (Alzheimer's disease, multiple sclerosis) neurodegeneration (Fontaine et al., 2002). Furthermore, the absence or blockage of other proinflammatory cytokines, such as interleukin $1 \beta$ (IL-1 $\beta$ ), has ameliorated the outcome of various neurodegenerative processes (Acarin et al., 2002; Park et al., 2005). However, conflicting evidence has arisen that supports a neuroprotective role for TNF- $\alpha$ and IL- $1 \beta$; it was reported that the blockage of proinflammatory IL- $1 \beta$ and TNF- $\alpha$ using fluorinated salicylate was neuroprotective in postnatal excitoxicity (Acarin et al., 2002), whereas TNF- $\alpha$ was found to be neuroprotective through nuclear factor $\kappa \mathrm{B}(\mathrm{NF}-\kappa \mathrm{B})$ activation in another model of excitotoxicity (Marchetti et al., 2004), and Carlson and colleagues (1999) found both IL-1 $\beta$ and TNF- $\alpha$ to be neuroprotective, although through distinct pathways. Thus, it can be concluded that the fate of neurons during neuroimmune insults involve mechanistically and spatially complex processes that are yet to be fully understood.

There have been many attempts to specifically block the effects of TNF- $\alpha$ or IL- $1 \beta$ in the brain to study their individual contribution in various pathological models. However, antibodies and antisense strategies against the two cytokines have led to inconclusive results, because such approaches do not completely block the activity of the cytokines, and only trace amounts of TNF- $\alpha$ and IL- $1 \beta$ are needed to activate their cognate receptors 
on target cells. Thus, transgenic mice lacking either TNF- $\alpha$ or IL- $1 \beta$ are frequently used to study the effect of these cytokines on various systems. This solution is not without its flaws: IL- $1 \beta$ and TNF- $\alpha$ are released by similar cells, have numerous overlapping actions, stimulate their own synthesis and that of each other, and both signal in their target cells through NF- $\kappa \mathrm{B}$ and cyclooxygenase mechanisms, leading to the release of common substrates such as prostaglandins (Abbas and Lichtman, 2003). Consequently, there is genuine concern and evidence that compensatory mechanisms by their cytokine counterpart exist in the transgenic mouse lines lacking either IL- $1 \beta$ or TNF- $\alpha$. This principle has been demonstrated recently by Tanabe and colleagues (2005) in a model of pulmonary infection in which IL- $1 \beta$ knock-out (KO) mice showed significantly higher levels of TNF- $\alpha$ in lung tissue compared with their wild-type counterparts and that this TNF- $\alpha$ played a major role in host defense against the pathogen. When such a situation arises, it can obfuscate some crucial contribution of an individual cytokine that another would not participate in under physiological and/or pathological processes. Taking this into consideration and to prevent confusion as to the specific actions of the two cytokines, we have generated a new exciting transgenic mouse deficient in both IL- $1 \beta$ and TNF- $\alpha$ genes. IL- $1 \beta$, TNF- $\alpha$, and IL- $1 \beta$ / TNF- $\alpha$ double KO mice provide us with a powerful tool to tease out the individual effects of both cytokines and control for compensatory mechanisms that might exist. Furthermore, the use of these three stains of $\mathrm{KO}$ mice could elucidate effects that are specific to a single cytokine (individual $\mathrm{KO}$ ) or that can be attributed to a more general NF- $\kappa \mathrm{B}$-dependent inflammatory process (double $\mathrm{KO}$ ).

To study the role of innate immunity and proinflammatory cytokines in neurodegeneration and protection, the use of sodium nitroprusside (SNP) is an interesting candidate, because it causes an acute and localized excitotoxic cell death when infused within the brain parenchyma (Blais and Rivest, 2004). This damage is also associated with a transient inflammatory response, which has been well characterized by our group (Blais and Rivest, 2004). Although the addition of exogenous TNF- $\alpha$ was proven to exacerbate the neurodegenerative processes in this model, the role of endogenously produced IL-1 and TNF during excitotoxicity still needs to be clarified. Here, we used the transgenic mice lacking the gene encoding for IL- $1 \beta$, TNF- $\alpha$, or both cytokines and challenged them with SNP intracerebrally. Surprisingly, mice lacking TNF and both cytokines had severe and widespread neurodegeneration and demyelination, which was associated with attenuated early microglial reactivity and a robust inflammatory response later on. IL- $1 \beta$ did not alter the innate immunity or scale bar, $250 \mu \mathrm{m}$.
Table 1. Plasmids and enzymes used for the synthesis of the CDNA probes

\begin{tabular}{lcll}
\hline & & \multicolumn{2}{l}{ Linearizing enzymes } \\
\cline { 3 - 4 } Plasmid & Length (bases) & Sense probe & Antisense probe \\
\hline Mouse IL-1 $\beta$ & 1360 & Xhol/SP6 & Kpnl/T7 \\
Mouse TNF- $\alpha$ & 419 & Hindll//T7 & Xhol/SP6 \\
Mouse TLR2 & 2278 & SPEl/T7 & EcoRV/SP6 \\
Mouse MCP-1 & 578 & Sacl/SP6 & BamHI/T7 \\
Mouse MBP & 481 & Xbal/SP6 & BamHI/T7 \\
Mouse PLP1 & 813 & Xbal/SP6 & BamHI/T7 \\
\hline
\end{tabular}

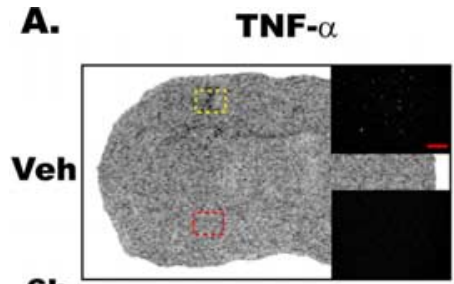

6h
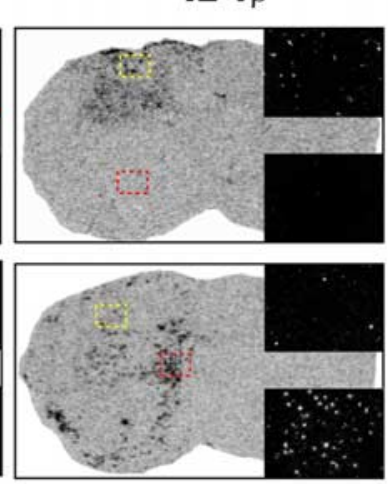

4d

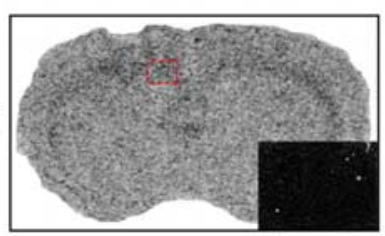

7d
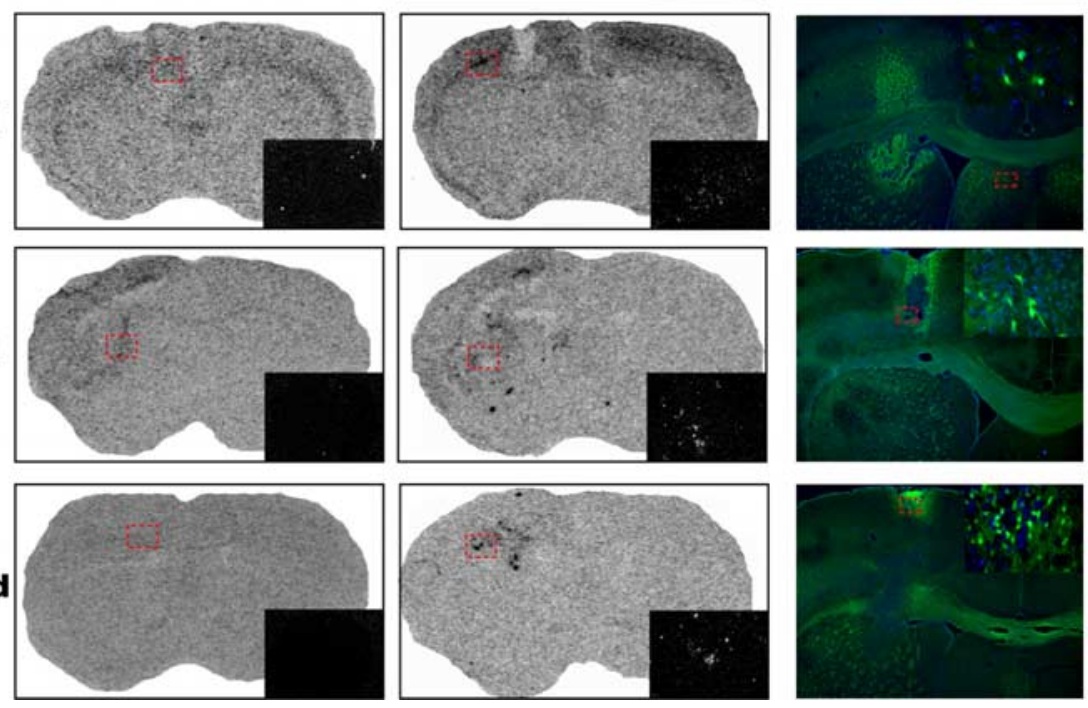

Injection Site

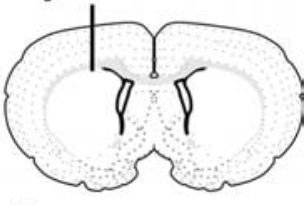

B. FJB
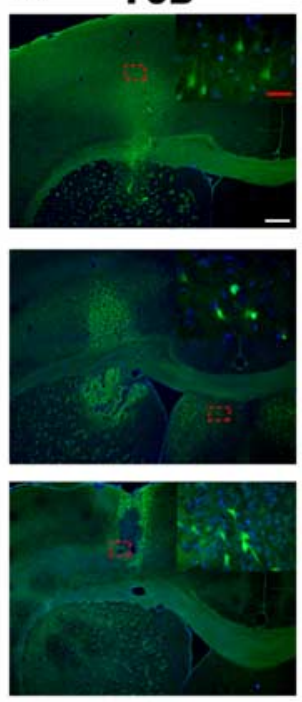

Figure 1. Proinflammatory cytokine expression and neurodegeneration after intracerebral sodium nitroprusside injection. $\boldsymbol{A}$, Representative photomicrographs of in situ hybridization signals showing the expression of TNF- $\alpha$ mRNA (left) and IL- $1 \beta$ mRNA (right) in the brains of mice that received an intraparenchymal injection of the excitotoxin SNP versus vehicle saline (Veh) and killed $6 \mathrm{~h}, 4 \mathrm{~d}, 7 \mathrm{~d}$, and $14 \mathrm{~d}$ after the injection. The coronal sections ( $25 \mu \mathrm{m}$ ) were taken from $\mathrm{x}$-ray films (exposed for $3 \mathrm{~d}$; Biomax MR; Kodak), whereas the dark-field photomicrographs (insets) were taken from the same brain slices but dipped into NTB emulsion milk (Kodak). The yellow boxes relate to the hybridization signal for the cytokines at the cannula tract and are magnified in the top inset, whereas the red boxes represent parenchymal signals caused by SNP and are magnified in the bottom inset. Please note the transient TNF- $\alpha$ expression that fades completely by $14 \mathrm{~d}$, whereas the IL- $1 \beta$ signal is still present after $14 \mathrm{~d}$. The top right of the figure shows the location of the injection site in the dorsal basal ganglia. Scale bar, $100 \mu \mathrm{m}$. $\boldsymbol{B}$, Fluorescent photomicrographs depicting representative examples of FJB staining, which indicates neuronal death (green neurons) in adjacent sections taken from the same mice as in $\boldsymbol{A}$. The sections were counterstained with DAPI (blue nuclei). Note the rapid onset of neuronal cell death $6 \mathrm{~h}$ after SNP injection, which peaked at $4 \mathrm{~d}$ and persisted up to time $14 \mathrm{~d}$ after SNP injection. Red scale bar, $25 \mu \mathrm{m}$; white

change the extent of neuronal death and demyelination. Therefore, TNF- $\alpha$ has clear beneficial actions in triggering innate immunity during acute brain injury.

\section{Materials and Methods}

IL- $1 \beta$ and TNF- $\alpha$ transgenic mice. IL- $1 \beta$ knock-out mice (C57BL/ 6 background) were generously provided by Dr. H. Zheng (Merck Research 


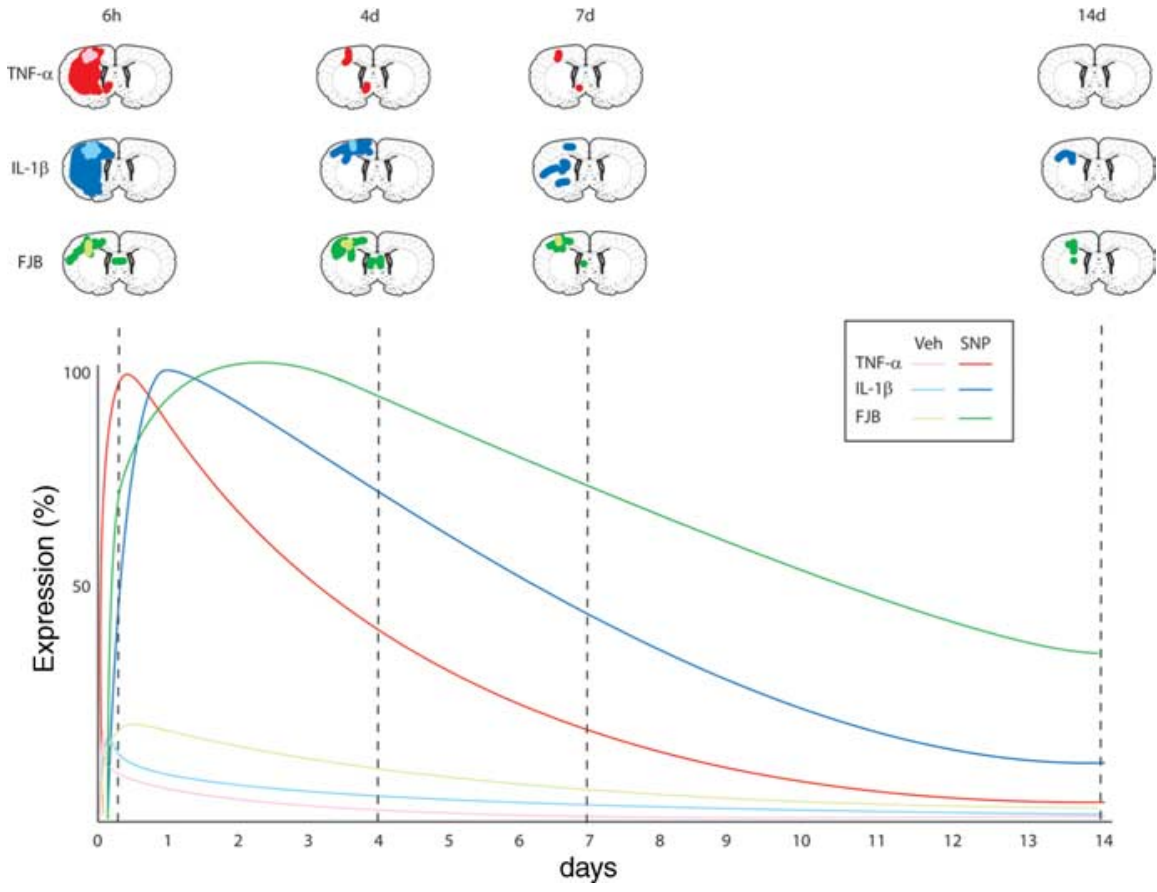

Figure 2. Schematic representation of TNF- $\alpha$-, IL-1 $\beta$-, and FJB-expressing regions in the mouse brain after a single intraparenchymal bolus of SNP. The top panel shows the areas that had positive signal for TNF- $\alpha$ mRNA, IL- $1 \beta$ mRNA, and FJB (dark colors) compared with their vehicle saline controls (Veh; light colors). The bottom panel depicts the time-related profile of the two cytokine transcripts and the marker of neuronal death in response to the excitotoxic insult. Please note the sharp and transient expression of the gene encoding IL-1 $\beta$ and TNF- $\alpha$ in response to intracerebral SNP. Neurodegeneration as revealed by FJB progressively increased during the first $4 \mathrm{~d}$, and positive signal was still detectable at time $14 \mathrm{~d}$ after SNP injection. TNF- $\alpha$ expression returned to basal level at that time.

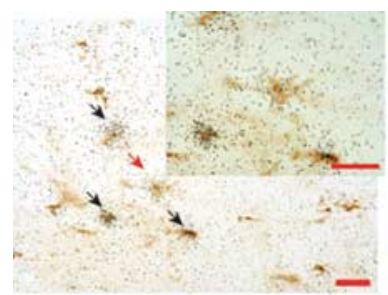

TNF-O

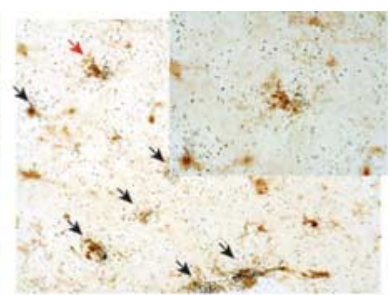

$\mathrm{IL}-1 \beta$

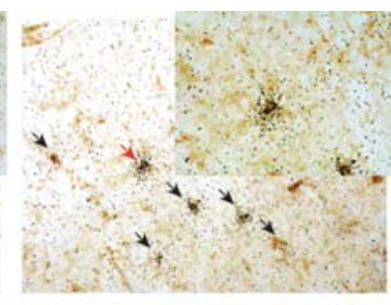

TLR2
Figure 3. The genes encoding TNF- $\alpha, I L-1 \beta$, and TLR 2 are expressed in microglial cells in the brains of mice administered with SNP. Parenchymal microglial cells were labeled by immunoperoxidase technique using an antisera directed against ionized calcium binding adapter molecule 1 (iba1-ir) in brain sections of mice killed $6 \mathrm{~h}$ after the intracerebral SNP injection. TNF- $\alpha$, IL-1 $\beta$, and TLR2 mRNA were thereafter hybridized on the same sections by means of a radioactive in situ hybridization technique (silver grains). Note that all three mRNAs are specifically detected in iba1-ir cells (arrows). The red arrows refer to double-labeled cells enhanced in the inset. Scale bar, $25 \mu \mathrm{m}$ at both magnifications.

Laboratories, Rahway, NJ) and generated as described previously (Zheng et al., 1995; Laflamme et al., 1999). TNF- $\alpha$ knock-out mice [mixed C57BL/6 ( $\sim 50 \%)$ and 129 S6 ( $~ 50 \%)$ background] were obtained commercially (The Jackson Laboratory Bar Harbor, ME) and generated through breeding procedures. To obtain homogeneity in background, the IL-1 $\beta /$ TNF- $\alpha$ double knock-out mice were obtained by crossing four single knock-out mice from both strains, obtaining offspring that is heterozygous for both genes (i.e., IL- $1 \beta^{+/-} / \mathrm{TNF}-\alpha^{+/-}$). This heterozygote offspring was intercrossed to obtain breeding pairs of the following genotypes: wild-type control mice (IL- $1 \beta^{+/+} / \mathrm{TNF}-\alpha^{+/+}$), IL- $1 \beta$ knock-outs (IL- $1 \beta^{-/-} /$TNF- $\alpha^{+/+}$), TNF- $\alpha$ knock-outs (IL- $1 \beta^{+/+} /$TNF- $\alpha^{-1-}$ ), and double knock-outs (IL-1 $\beta^{-1-} /$ TNF- $\alpha^{-1-}$ ). The colonies used in our experiments were established by intercrossing the mice from each family within a genotype for at least three generations. Thus, by using multiple breeding families within each group coming from the same four common ancestral breeding pairs, the homogeneity of background within and between the genotypes was increased greatly.
Genotypes were determined by PCR on DNA samples from the tails and/or ear punches of the mice. Primers used for the IL- $1 \beta$ wild-type gene were $5^{\prime}$-CTGTGGCAGCTACCTGTGTC-3' and $5^{\prime}$-TTGGCAAGTCAATGGTTGAG-3', yielding a 310 base pair (bp) product. The primers for IL- $1 \beta$ knock-out gene were $5^{\prime}$ TGATGCCGCCGTGTTC-3' and 5'-TAAAGCACGAGGAAGCGGTCA-3', yielding a 636 bp product. For determining the TNF- $\alpha$ genotype, a single set of primer was used, $5^{\prime}$ GAAAAGCAAGCAGCCAACCAG- $3^{\prime}$ and $5^{\prime}$ GTCCAACCCACGGCTTC-3', yielding a 646 bp product for the wild-type gene and a $1357 \mathrm{bp}$ product for the knock-out gene. The PCR products were then resolved and visualized on a $0.7 \%$ agarose gel.

Adult male mice of all groups (body weight, $30-35 \mathrm{~g}$ ) were group-housed in microisolators in standard laboratory conditions $(14 / 10 \mathrm{~h}$ light/dark cycle; lights on at 6:00 A.M. and off at 8:00 P.M.; room temperature at $23 \pm 1{ }^{\circ} \mathrm{C}$ ) with ad libitum access to mouse chow and water. Each mouse was only used once for experimentation, and all protocols were performed according to the Canadian Council on Animal Care guidelines and were approved by the Animal Welfare Committee of Laval University. A total of 107 mice were assigned to different protocols (four to seven mice per group), each corresponding to different treatments and postinjection (p.i.) times. Paired vehicle-treated mice of all groups were also killed at corresponding times after the SNP injection.

Experimental protocol. Mice were anesthetized with isofluorane and placed in a stereotaxic apparatus (Kopf Instruments, Tujunga, CA) equipped with an isofluorane mask to maintain anesthesia. The striatum was then reached $(-2.0 \mathrm{~mm}$ lateral and $-3.0 \mathrm{~mm}$ dorsoventral to the bregma) with a 33 gauge stainless-steel cannula (Plastics One, Roanoke, VA) that was connected to a $50 \mu$ l Hamilton syringe with intramedic polyethylene tubing (PE-50; Caly Adams, Parsipanny, NJ). A volume of $1 \mu$ l containing $5 \mu \mathrm{g}$ of SNP diluted in sterile saline was infused over 2 min by means of a microinjection pump (model A-99; Razel Scientific Instruments, Stanford, CT). These coordinates were selected on the basis of data obtained from previous experiments (Blais and Rivest, 2004) and do not mimic a particular neurodegenerative disease, but they were used to represent an acute mechanism of immune response and neurodegeneration/excitotoxicity in the cerebral tissue. At different times after the injection ( $6 \mathrm{~h}, 4 \mathrm{~d}, 7 \mathrm{~d}$, and $14 \mathrm{~d})$, mice were anesthetized deeply via an intraperitoneal injection $(100 \mu \mathrm{l})$ of a mixture of ketamine hydrochloride $(91 \mathrm{mg} / \mathrm{ml})$ and xylazine $(9.1 \mathrm{mg} / \mathrm{ml})$ and then rapidly perfused transcardially with $0.9 \%$ saline, followed by $4 \%$ paraformaldehyde in 0.1 м borax buffer, $\mathrm{pH} 9.0$, at $4^{\circ} \mathrm{C}$.

In situ hybridization histochemistry, immunocytochemistry, and FluoroJade B staining. After transcardiac perfusions, brains were removed rapidly from the skull, postfixed for $1-3 \mathrm{~d}$, and then placed in a solution containing $20 \%$ sucrose diluted in $4 \%$ paraformaldehyde-borax buffer $\mathrm{pH} 9.0$, overnight at $4^{\circ} \mathrm{C}$. The frozen brains were mounted on a microtome (Reichert-Jung; Cambridge Instruments, Deerfield, IL) and cut into $25 \mu \mathrm{m}$ coronal sections from the olfactory bulb to the caudal medulla. The slices were collected in a cold cryoprotectant solution and stored at $-20^{\circ} \mathrm{C}$. Every 12th section was mounted on Colorfrost/Plus 
microscope slides (Fisher Scientific, Pittsburgh, PA), and in situ hybridization histochemical localization was performed using an antisense riboprobe according to a protocol described previously (Blais and Rivest, 2004). Riboprobes for the proinflammatory cytokines IL- $\beta$ and TNF- $\alpha$, the toll-like receptor type 2 (TLR2; a marker of microglial activation), monocyte chemoattractant protein 1 (MCP-1; marker of chemotaxis and monocyte recruitment), myelin basic protein (MBP), and proteolipid protein 1 (PLP1) (markers for oligodendrocytes), were used [for details, see Blais and Rivest (2004)] (Table 1). Immunocytochemistry was combined with the in situ hybridization protocol to determine whether IL- $1 \beta$, TNF- $\alpha$, and TLR2 were expressed in microglia. Anti-ionized calcium binding adapter molecule 1 (ibal) labeled cells of myeloid lineage (macrophages and microglia), which was followed by in situ hybridization for the three genes of interest as described in previous work (Turrin and Rivest, 2004).

Confirmation of neuronal death was determined via the Fluoro-Jade B (FJB) method. Mounted brain sections were dried under vacuum for $2 \mathrm{~h}$, dehydrated through graded concentrations of alcohol (50, 70, and 100\%; 1 min), rehydrated through graded concentrations of alcohol (100, 70, and 50\%; 1 min each), and rinsed for $1 \mathrm{~min}$ in distillated water. They were then dipped and shaken in potassium permanganate $(0.06 \%)$ for $10 \mathrm{~min}$, rinsed for $1 \mathrm{~min}$ in distilled water, dipped, and shaken in a solution containing $0.004 \% \mathrm{FJB}$ (Histochem, Jefferson, AR), $0.1 \%$ acetic acid, and $0.0002 \%$ 4',6-diamidino-2-phenylindole (DAPI) (Invitrogen, Burlington, Ontario, Canada) for 20 min. The slides were thereafter rinsed three times in distilled water ( $1 \mathrm{~min}$ each), dried, dipped in xylene three times ( 2 min each), and coverslipped with distrene plasticizer xylene mounting media (Electron Microscopy Science, Washington, PA).

Data analysis. The relative area and/or intensity of mRNA signals were measured on Biomax MR x-ray films (Kodak, Rochester, NY). Transmittance values (referred to in this study as OD) and area of positive hybridization signal were measured under a Northern Light desktop illuminator (Imaging Research, Ste-Catherine's, Ontario, Canada) using a Sony (Tokyo, Japan) camera video system attached to a MicroNikkor $55 \mathrm{~mm}$ Vivitar extension tube set for a Nikon (Montréal, Quebec, Canada) lens and coupled to a Dimension GX270 personal computer (Dell Computer, North York, Ontario, Canada) and ImageJ software (version 1.23; W. Rasband, National Institutes of Health, Bethesda, MD). The OD for each pixel was calculated using a known standard of intensity and distance measurements from a logarithmic specter adapted from BioImage Visage 110s (Millipore, Ann Arbor, MI). Sections from experimental and control animals were digitized and subjected to densitometric analysis, yielding average OD and signal area. The OD for each section was corrected for the average background signal. To standardize the sampling procedure, up to a maximum of 12 sections showing the most intense signal for each brain were analyzed. The sections corresponded approximately to the bregma +0.98 to $-2.80 \mathrm{~mm}$ sections in the brain atlas by Paxinos and Franklin (2001).

Visualization of FJB-positive regions from the slides was done using a
LL-1 KO TNF KO DbI KO
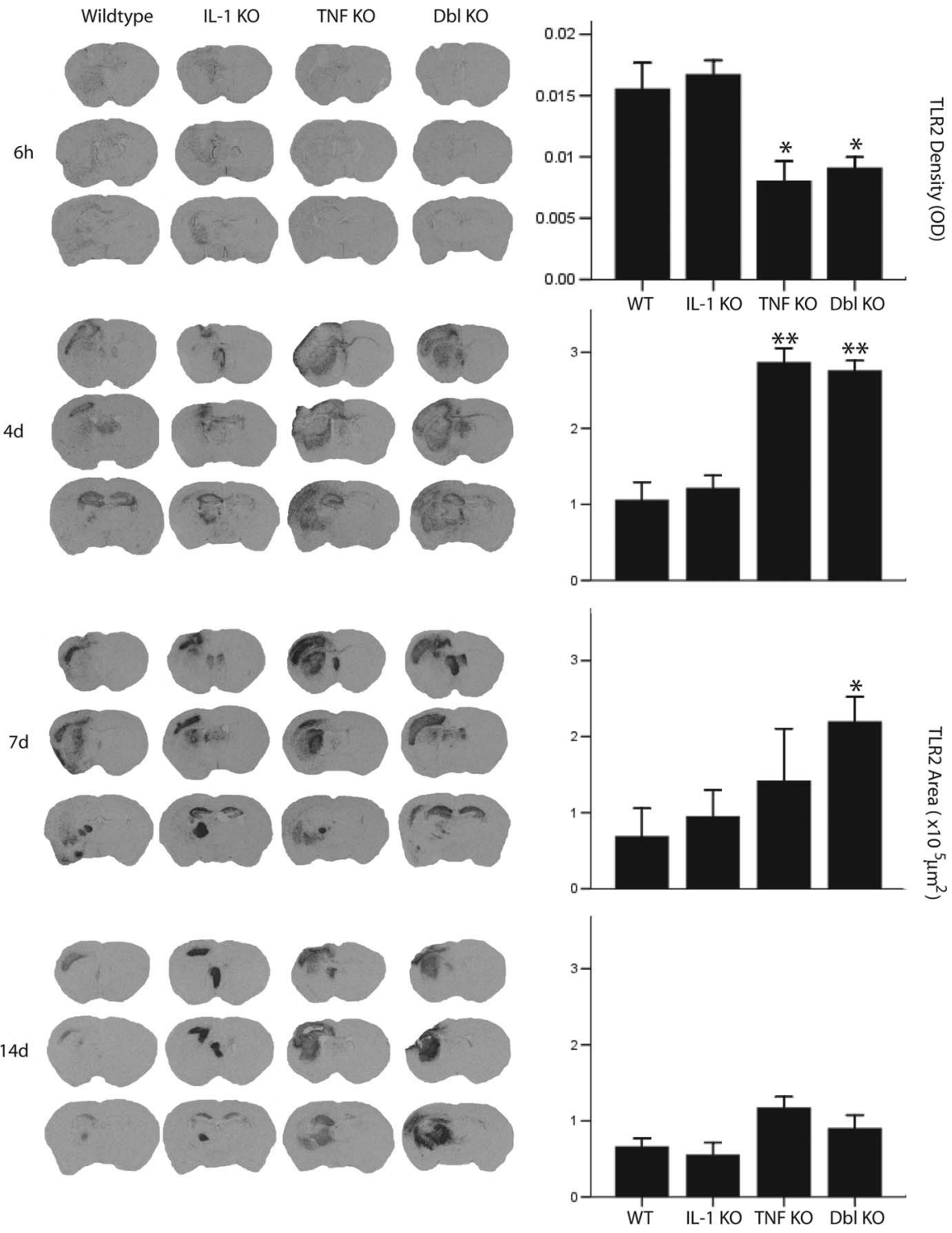

Figure 4. Time-related transcriptional activation of TLR2 in the brains of IL- $1 \beta$, TNF- $\alpha$, and IL-1 $\beta / T$ TNF- $\alpha$ double (DbI) K0 mice that received an intraparenchymal injection of SNP. The coronal sections ( $25 \mu \mathrm{m}$; $x$-ray films; exposed for $3 \mathrm{~d}$; Biomax MR; Kodak) were taken from mice killed $6 \mathrm{~h}, 4 \mathrm{~d}, 7 \mathrm{~d}$, or $14 \mathrm{~d}$ after the excitotoxic insult. The right panels depict the quantitative analyses of the density $(6 \mathrm{~h})$ or area $(4,7$, and $14 \mathrm{~d})$ of TLR2 mRNA signal at each time point $\left[{ }^{*} p<0.05\right.$ compared with wild type (WT) and IL, $p<01$ compared with WT and IL-1 K0; data presented as mean \pm SEM]. Please note the robust signal for TLR2 (index o microglial activation) in the cortex, basal ganglia, lateral septal nucleus, hippocampus, and ventral posterior thalamic nuclei. Note mice. Indeed, whereas a lower signal was detected in the brains of these animals at time $6 \mathrm{~h}$, at $4 \mathrm{~d}$, the areas containing TLR2-expressing cells were larger in the TNF and Dbl KO mice than in IL-1 KO and WT animals. This trend was also present in the cerebral cortex, septum, hippocampus, and basal ganglia of Dbl KO mice at time $7 \mathrm{~d}$.

C-80 Nikon microscope and super-high-pressure mercury lamp (Nikon) fitted with a Retiga EXi Fast digital camera (QImaging, Burnaby, British Columbia, Canada) feeding to a Precision 660 workstation (Dell Computer). The FJB-positive regions were traced on a Wacom (Vancouver, WA) pen tablet using the Neurolucida stereological software package (version 6.02.1; MicroBrightField, Williston, VT), and threedimensional (3D) reconstruction and volume determination were compiled using Neuroexplorer software (version 4.01.1; MicroBrightField). To standardize the sampling procedure, up to a maximum of nine sections (bregma +0.98 to $-2.18 \mathrm{~mm}$ ) showing the most intense signal for each brain were analyzed. Data are reported as mean \pm SEM values for experimental and control mice.

Statistical analysis. Data were compiled and the statistical analysis was performed using SPSS (Chicago, IL) software (version 13.0). Between- 
6h WT

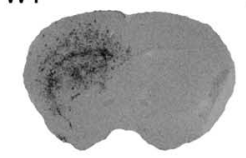

IL-1 KO

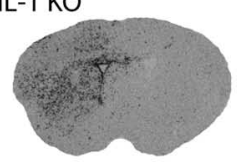

TNF KO

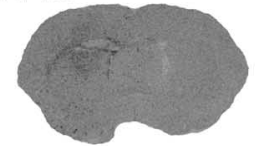

Dbl KO

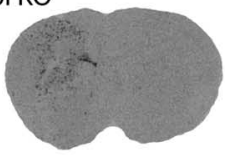

4d WT

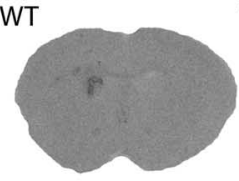

IL-1 KO

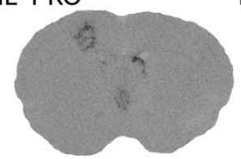

TNF KO

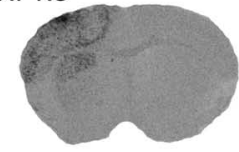

Dbl KO

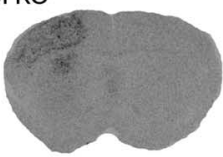

7d WT

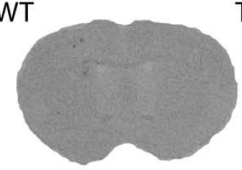

TNF KO

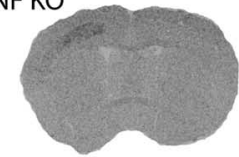

IL-1 KO

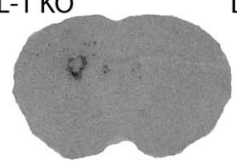

14d WT

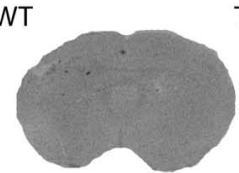

Dbl KO

$\mathrm{IL}-1 \mathrm{KO}$

$\mathrm{Dbl} \mathrm{KO}$

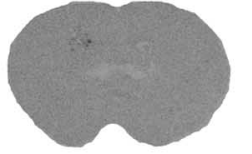

TNF KO
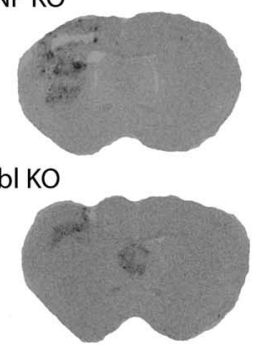
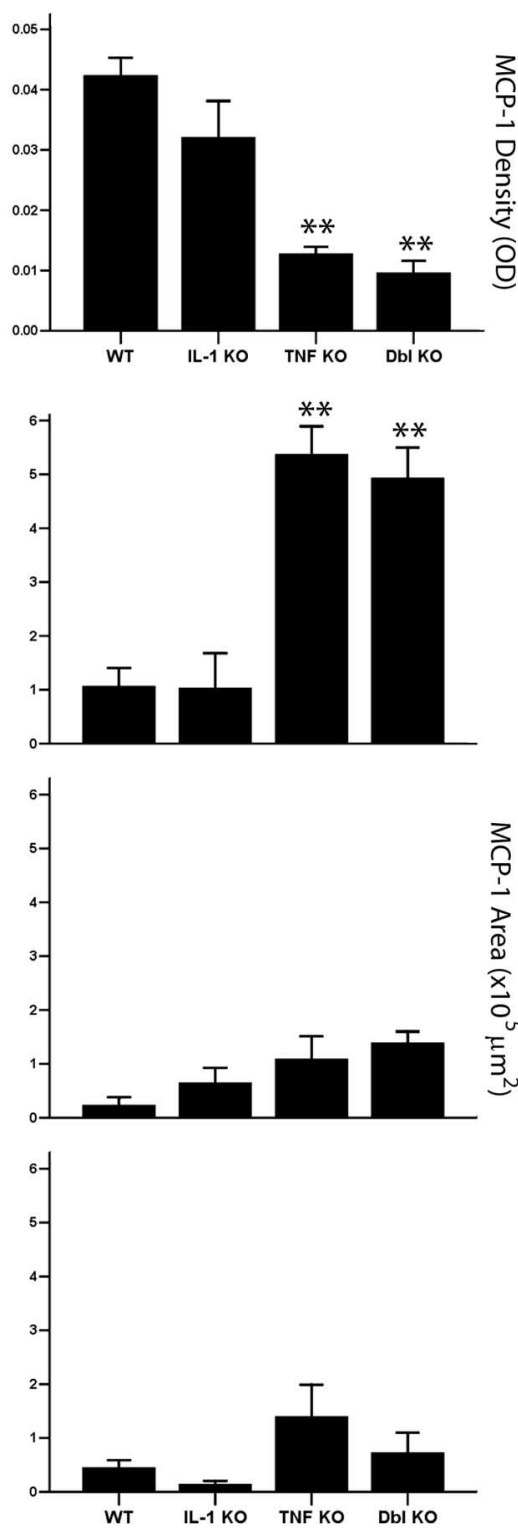

Figure 5. Time-related transcriptional activation of MCP-1 in the brains of IL-1 $\beta$, TNF- $\alpha$, and IL-1 $1 \beta / \mathrm{TNF}-\alpha$ double (Dbl) K0 mice that received an intraparenchymal injection of SNP. The coronal sections ( $25 \mu \mathrm{m}$; $\mathrm{x}$-ray films; exposed for $3 \mathrm{~d}$; Biomax MR; Kodak) were taken from mice killed $6 \mathrm{~h}, 4 \mathrm{~d}, 7 \mathrm{~d}$, or $14 \mathrm{~d}$ after the excitotoxic insult. The right panels depict the quantitative analyses of the density $(6 \mathrm{~h})$ or area $(4,7$, and $14 \mathrm{~d})$ of MCP-1 mRNA signal at each time point ${ }^{* * *} p<0.01$ compared with wild type (WT) and IL-1 K0; data presented as mean \pm SEM]. Please note the robust signal for MCP-1 (index of chemotaxis activation) at $6 \mathrm{~h}$ in wild-type and IL-1 KO mice. Appreciate the very interesting switch in the intensity of hybridization signal for MCP-1 at time $6 \mathrm{~h}$ and $4 \mathrm{~d}$ postinjection in the brain of TNF and Dbl KO mice. Although the signal intensity was lower in the brains of these animals at time $6 \mathrm{~h}$, at $4 \mathrm{~d}$, the areas containing MCP-1-expressing cells were larger in the TNF and Dbl KO mice than in IL-1 KO and WT animals. This trend was also present in the TNF and Dbl KO mice at time $7 \mathrm{~d}$.

group differences of mRNA expression area or density and FJB volume were analyzed using ANOVA. Comparisons between means of main effects were conducted by Bonferonni-corrected $t$ tests. Likewise, for significant interactions, Bonferonni-corrected $t$ tests were used to compare means of the simple effects comprising these interactions.

\section{Results}

Cytokine gene expression in the brain of SNP-challenged mice

We have reported previously that a single bolus with the nitric oxide (NO) donor SNP was able to cause neurodegeneration, which was modulated by coadministration of cytokines (Blais and Rivest, 2004). To determine whether IL- $1 \beta$ and TNF- $\alpha$ genes

were induced in this model, in situ hybridization was performed across the brain of mice at various times after SNP infusion. As expected, transcriptional activation of both IL- $1 \beta$ and TNF- $\alpha$ mRNAs took place as early as $6 \mathrm{~h}$ after the SNP insult. Although vehicle infusion also caused an increase in both cytokine transcripts, the message was localized within the area of the cannula and rarely extended below the site of infusion (Fig. 1, top). The stress of infusion was also very transient, and the hybridization signal returned to basal levels at time $4 \mathrm{~d}$ p.i. On the other hand, IL$1 \beta$ - and TNF- $\alpha$-expressing cells were found almost throughout the entire hemisphere of mice that received SNP and were killed 6 h thereafter (Fig. $1 A$ ). The TNF- $\alpha$ mRNA signal slowly returned to undetectable level by day 14 p.i., whereas the IL- $1 \beta$ mRNA was still expressed at that time (Figs. 1, 2). Double labeling combining immunocytochemistry and in situ hybridization pointed toward microglia as being the main cell type to produce both cytokines (Fig. 3).

The expression of these proinflammatory cytokines is paralleled by the neuronal cell death in the SNP-treated brains, as indicated by FJB staining (Fig. $1 B$ ). The FJB signal increased to a maximum between 1 and $4 \mathrm{~d}$ after SNP injection and slowly decreased thereafter, but it was still present at time $14 \mathrm{~d}$ p.i. These results provide clear evidence that transcriptional activation of both IL- $1 \beta$ and TNF- $\alpha$ genes takes place along the neurodegenerative process in the CNS of SNP-injected mice.

\section{Role of IL-1 $\beta$ and TNF- $\alpha$ in microglial activation and CNS damages}

The rapid increase in microglial-derived IL- $1 \beta$ and TNF- $\alpha$ in degenerating regions indicates a potential role of these cytokines in SNP-induced excitotoxicity. However, both cytokines have numerous overlapping activities, and deletion of one cytokine may frequently be compensated by the other. To ascertain that there are no compensatory mechanisms, we generated a new mouse bearing two mutant transgenes. IL- $1 \beta^{-/-}$, TNF- $\alpha^{-l-}$, and IL- $1 \beta^{-/-} / \mathrm{TNF}-\alpha^{-/-}$and their wild-type littermates were generated through breeding procedures and received a single bolus of saline or SNP, as described above. We first looked at microglial reactivity using TLR2 gene expression. TLR2 mRNA is induced rapidly in activated microglia in response to wide variety of insults, and it is a reliable index of proinflammatory signaling in microglia/macrophages. Indeed, this transcript is not detectable in parenchymal microglia under basal conditions, but a strong increase in TLR2 gene transcription takes places only in microglia/macrophages and not other cell types in the brain of mice treated with SNP (Fig. 3), bacterial products, or various models of CNS injuries (Nguyen et al., 2002; 
Laflamme et al., 2003; Blais and Rivest, 2004; Turrin and Rivest, 2004).

Over time, TLR2 was found to be upregulated in regions proximal and distal to the SNP injection site, including the frontal cortex, hippocampus, basal ganglia, septum, and ventral posterior thalamic nuclei (Fig. 4). Early microglial activation in the brains of IL-1 KO, TNF KO, and double KO mice (as well as their wild-type controls) was determined by measuring the density (OD) of TLR2 mRNA expression on $x$-ray film (Fig. 4, right). The one-way ANOVA revealed differences in TLR2 OD between the genotypes $\left(F_{(3,14)}=8.883 ; p=0.002\right)$. As seen in Figure 4 and confirmed by post hoc tests, TNF and double knock-out mice showed a lower level of TLR2 mRNA density than their wild-type controls ( $p=0.035$ and 0.023 , respectively), suggesting a blunted early inflammatory response, whereas the IL-1 knock-outs were not different from controls. The MCP-1 gene was also found to be significantly different between the genotypes $\left(F_{(3,15)}=24.64 ; p<\right.$ 0.001 ) and less intense in TNF and double knock-out mice compared with the wild-type controls ( $p<0.001$ for both) and IL-1 knock-outs ( $p=0.001$ and 0.009 , respectively), suggesting that the chemotaxic response was also delayed (Fig. 5). For later time points, because TLR2 expression was often very intense and widespread, the area of TLR2-positive signal on the $\mathrm{x}$-ray films was used as a more reliable measure. The two-way ANOVA revealed the area expressing TLR2 varied as a function of the genotype-by-time interaction $\left(F_{(6,44)}=3.068\right.$; $\left.p=0.014\right)$. Interestingly, post hoc tests revealed that TNF and double knock-outs showed significantly larger areas of TLR2 expression $4 \mathrm{~d}$ after SNP injection ( $p<0.001$ for both) compared with their wildtype counterparts and IL- $1 \beta$-deficient mice. Although this trend was also observed $7 \mathrm{~d}$ after the SNP treatment, it was only found to be significant for the double knock-out mice ( $p=0.027$ ). Again, IL-1 knock-out mice were found not to be different from wild type. Similarly, the hybridization signal for the chemokine MCP-1 varied as a function of the genotype-by-time interaction $\left(F_{(6,50)}=9.959 ; p<0.001\right)$. MCP-1-expressing areas were significantly greater ( $p<0.001$ for all comparisons) in TNF and double knock-out mice compared with the IL-1 knock-out and wildtype mice $4 \mathrm{~d}$ after SNP treatment. At later time points, although this trend persisted, there were no differences between the groups (Fig. 5). Together, these data suggest that the absence of TNF- $\alpha$ results in a blunted early inflammatory and chemotaxic response to the SNP insult but an exaggerated activation of this response and microglia over time. Conversely, the absence of IL- $1 \beta$ does not seem to affect TLR2 and MCP-1 expression in response to SNP treatment.

\section{The absence of TNF- $\alpha$ prompts to a greater neuronal cell death and demyelination in response to an acute SNP challenge}

As mentioned, microglia activation paralleled the neuronal cell death after SNP administration (Fig. 1). Using stereological analysis, the regions showing neuronal cell death (as indicated by FJB-positive neurons) were analyzed by reconstructing threedimensional volumes from FJB-positive areas from serial brain slices of wild-type, IL-1, TNF, and double KO mice treated with SNP (Fig. $6 a$ and supplemental Movies 1-4, available at www.jneurosci.org as supplemental material). These results were quantified, and the volume of FJB-positive staining was found to vary as a function of the genotype-by-time interaction $\left(F_{(9,61)}=\right.$ $14.825 ; p<0.001)$. Post hoc tests revealed significant increases in neuronal death volume $4 \mathrm{~d}$ after SNP treatment in TNF- $\alpha$ and IL- $1 \beta /$ TNF- $\alpha$ double knock-out mice compared with their wild-
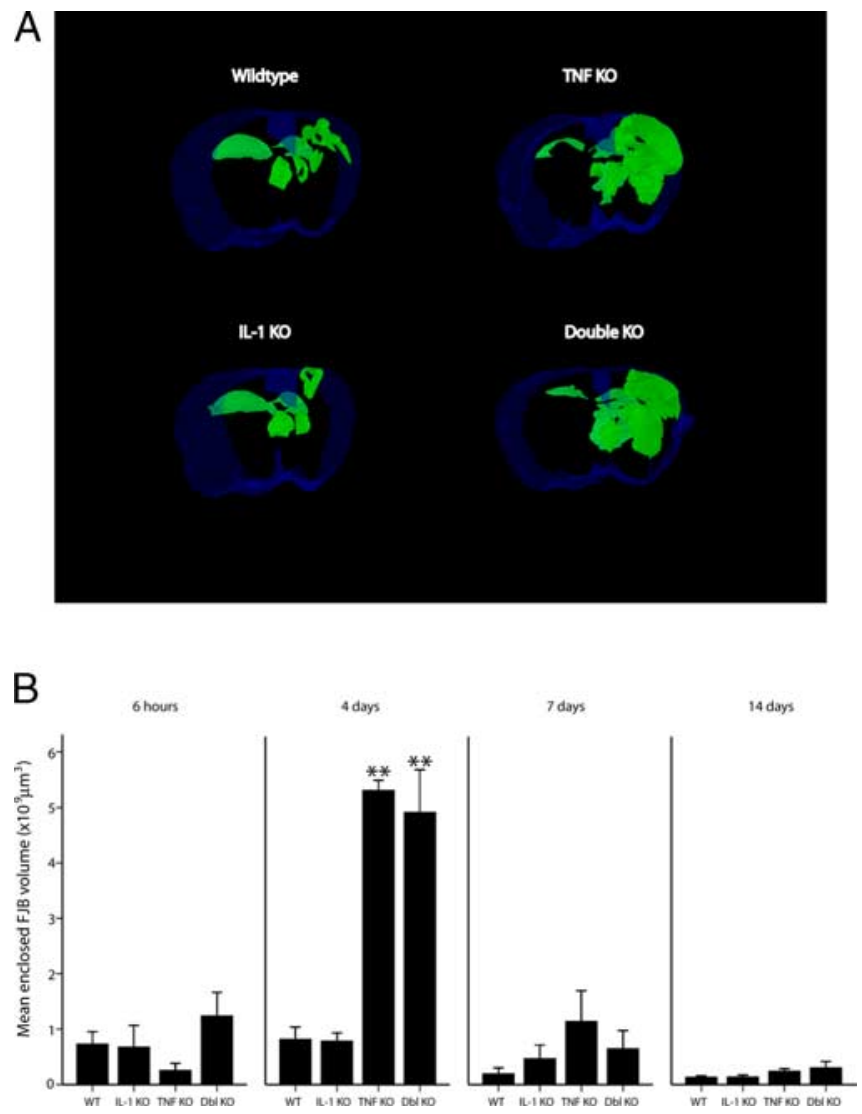

Figure 6. Three-dimensional representation of the volume of neuronal cell death, as measured by FJB-positive staining in wild-type (WT), IL- $1 \beta$, TNF- $\alpha$, and IL- $1 \beta /$ TNF- $\alpha$ double (Dbl) KO mice killed $4 \mathrm{~d}$ after an intraparenchymal injection of the excitotoxin SNP. $\boldsymbol{A}$, These 3D reconstructions of FJB-positive regions were performed using a C-80 Nikon microscope and super-high-pressure mercury lamp (Nikon) fitted with a Retiga EXi Fast digital camera (QImaging) feeding to a Precision 660 workstation (Dell Computer). The FJB-positive regions were traced on a Wacom pen tablet using the Neurolucida stereological software package (version 6.02.1; MicroBrightField), and 3D reconstruction and volume determination were compiled using Neuroexplorer software (version 4.01.1; MicroBrightField). Please note the larger volumes of FJB in the TNF and DbI KO animals compared with that of wild-type and IL-1 KO mice. $\boldsymbol{B}$, Quantitative analysis of the FJB volume in the brains of wild-type, IL-1, TNF, and Dbl KO mice over time. Please note the rapid appearance of neuronal cell death $6 \mathrm{~h}$ after SNP injection and the marked spread of FJB staining ( ${ }^{* *} p<0.01$ compared with wild type and IL- $1 \mathrm{KO}$; data presented as mean \pm SEM) in the (NS of TNF and DbI KO $4 \mathrm{~d}$ after the single SNP infusion. For photomicrographs of the FJB staining, refer to Figures 1 and 8.

type controls ( $p<0.001$ for both groups) (Fig. 6b), whereas IL- $1 \beta$ knock-out mice were not different from their wild-type controls.

Measures of demyelination, as indicated by the disappearance of PLP1 and MBP gene expression in the brain of SNP-treated mice, were also undertaken to evaluate the extent of structural damage associated with the neuronal death observed. The area of decreased PLP1 expression was found to vary as a function of the genotype-by-time interaction $\left(F_{(6,44)}=10.640 ; p<0.001\right)$, and significantly greater loss of signal was found in the brain of TNF- $\alpha$ and IL- $1 \beta /$ TNF- $\alpha$ knock-out animals $4 \mathrm{~d}$ after the SNP injections (Fig. 7) ( $p<0.001$ for both genotypes). As illustrated in Figure 7, these results were supported by a similar differences in MBP expression $\left(F_{(6,44)}=13.335 ; p<0.001\right)$, which showed significant decreases of MBP expression in TNF- $\alpha$ and IL- $1 \beta$ / TNF- $\alpha$ double knock-out mice $4 \mathrm{~d}$ after the injections of SNP (Fig. $8 B)(p<0.001$ for both genotypes). Furthermore, the areas lacking expression of PLP1 and MBP were FJB-positive areas 


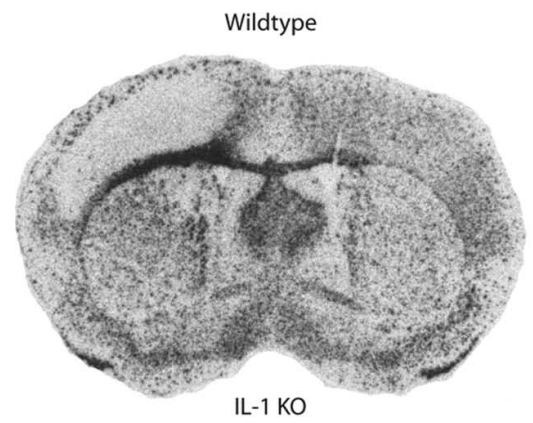

PLP1 mRNA

TNF KO
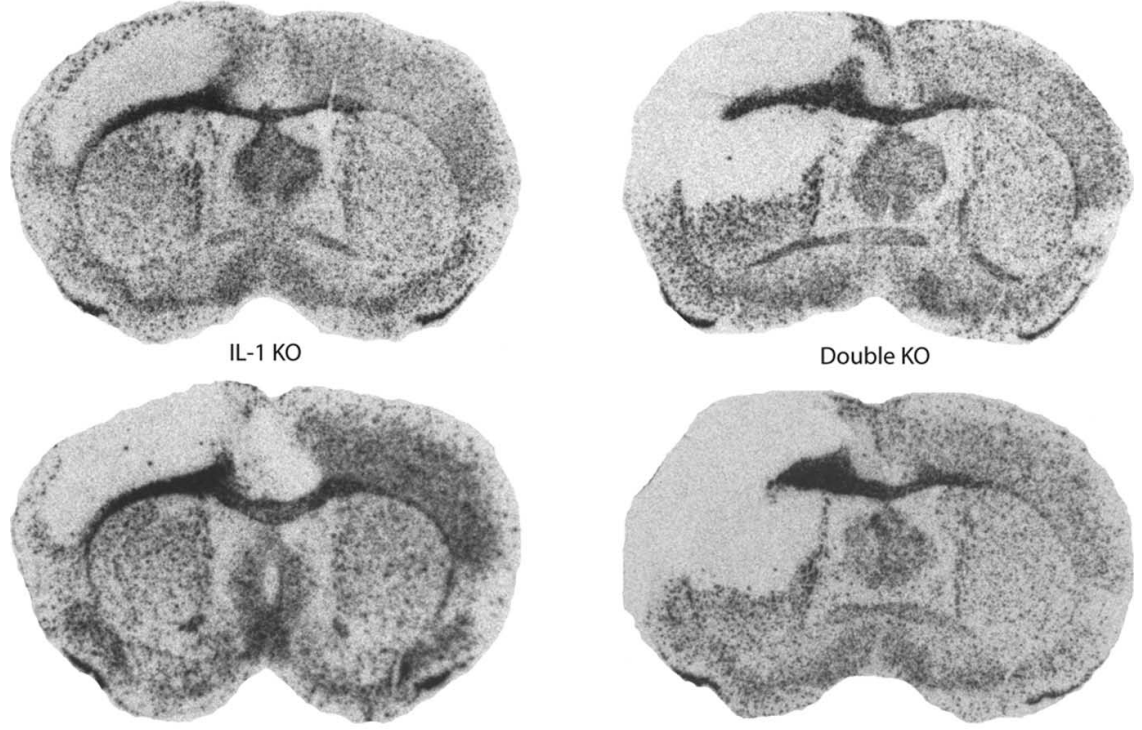

Double KO
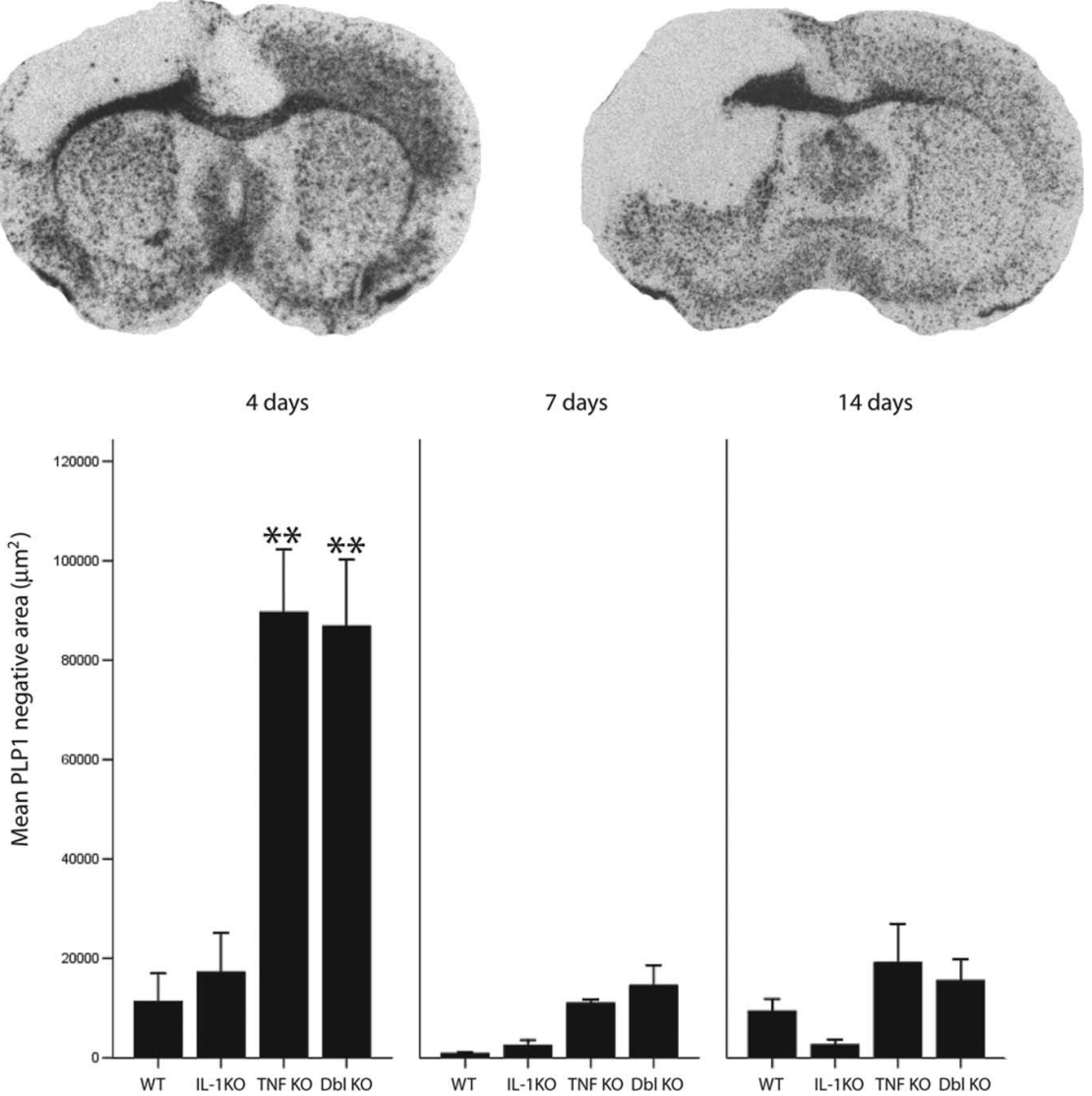

Figure 7. Expression of the gene encoding PLP1 (an oligodendrocyte marker) in the IL-1 $\beta$, TNF- $\alpha$, and IL- $1 \beta /$ TNF- $\alpha$ double (Dbl) KO mice that received a single intraparenchymal injection of SNP. The coronal sections ( $25 \mu \mathrm{m}$; $\mathrm{x}$-ray films; exposed for $3 \mathrm{~d}$; Biomax MR; Kodak) were taken from mice killed at time $4 \mathrm{~d}$ after SNP injection. PLP1 mRNA expression was used here as an index of demyelination (see the area with no hybridization signal in the ipsilateral side). The bottom panel depicts the quantitative analyses of such demyelination (area lacking PLP2 mRNA signal) at each time point. Please note the extent of the demyelination volume that was markedly larger in the ipsilateral side of TNF and TNF/IL-1 KO mice $4 \mathrm{~d}$ after SNP administration $\left[{ }^{* *} p<0.01\right.$ compared with wild-type (WT) and IL-1-deficient mice; data presented as mean \pm SEM].

(Fig. $8 \mathrm{~A}$, insets). Together, these results indicate the importance of the early rise in microglial-derived TNF- $\alpha$ during acute neuronal and myelin damages caused by the NO donor SNP. Such a rapid innate immune activity and TNF- $\alpha$ production is critical to limit the damage and restore brain homeostasis during an acute insult.

\section{Discussion}

As demonstrated previously, the NO donor SNP is able to cause significant neuronal death and demyelination when infused into the brains of mice (Blais and Rivest, 2004). Furthermore, the neurodegeneration caused by SNP is accompanied by microglial activation and the induction of the proinflammatory cytokines TNF- $\alpha$ and IL- $1 \beta$. In the previous study mentioned above, an injection of exogenous TNF- $\alpha$ was shown to exacerbate the damage and inflammation caused by SNP, and thus, TNF- $\alpha$ was suggested to play a detrimental role in SNP-associated neurodegeneration. Many studies have found similar results in supporting the neurotoxic effects of TNF- $\alpha$ and of IL-1 $\beta$ (Loddick and Rothwell, 1999; Sun et al., 2004; Viviani et al., 2004; Zou and Crews, 2005). However, there is evidence suggesting that innate immunity and proinflammatory cytokines play neuroprotective or neuroregenerative roles in the brain after neurotoxic insults or neuropathologies (Carlson et al., 1999; Arnett et al., 2001; Marchetti et al., 2004). Considering the debate, we used IL- $1 \beta$ - and TNF$\alpha$-deficient mice in a model of SNPinduced neurotoxicity to clarify the role of the endogenous proinflammatory cytokines in protecting or harming the brain during such an insult. Furthermore, because the two cytokines have similar properties and actions, we generated an IL- $1 \beta$ / TNF- $\alpha$ double knock-out mouse to prevent the possibility of compensatory mechanisms that could exist in the single knock-out mice (Tanabe et al., 2005). While not mimicking a specific neuropathology, the rapid and localized neurodegeneration and demyelination caused by the NO donor SNP when injected into the brain provides a very practical tool to study the role of the individual molecular players that can be involved in the immediate and consequent damage involved in neurodegenerative processes. In addition, the single and double cytokine knock-out mice used in combination with the SNP model allowed us to observe effects specific to TNF- $\alpha$, while at the same time confirming the absence of compensation by the similar cytokine IL- $1 \beta$.

The current experiment revealed that animals deficient in TNF- $\alpha$ (either the single or double knock-outs) showed dramatic exacerbation of the SNP-induced damage to neurons, as shown by a greater FJB-positive volume, and myelin, visualized by the absence of MBP and PLP1 gene expression at the same sites $4 \mathrm{~d}$ after the SNP intracerebral injection. Interestingly, the absence of TNF- $\alpha$ led to an early decrease of microglial activation and chemotaxis (measured by TLR 2 and MCP-1 mRNA expression, respectively), which later resulted in an exaggerated response by these cells. Not only does this prove that early endogenous TNF- $\alpha$ release after the SNP insult is neuroprotective, it also demonstrates that microglia of the brain can still be activated in the absence of two major proinflammatory cytokines. These results seem to oppose some of our previous findings (Blais and Rivest, 2004), in which endogenous TNF- $\alpha$ was given concomitantly with SNP intracerebral infusion and TNF- $\alpha$ was found to worsen the neuropathological consequences of the NO donor. This suggests that the source, timing, and dose 

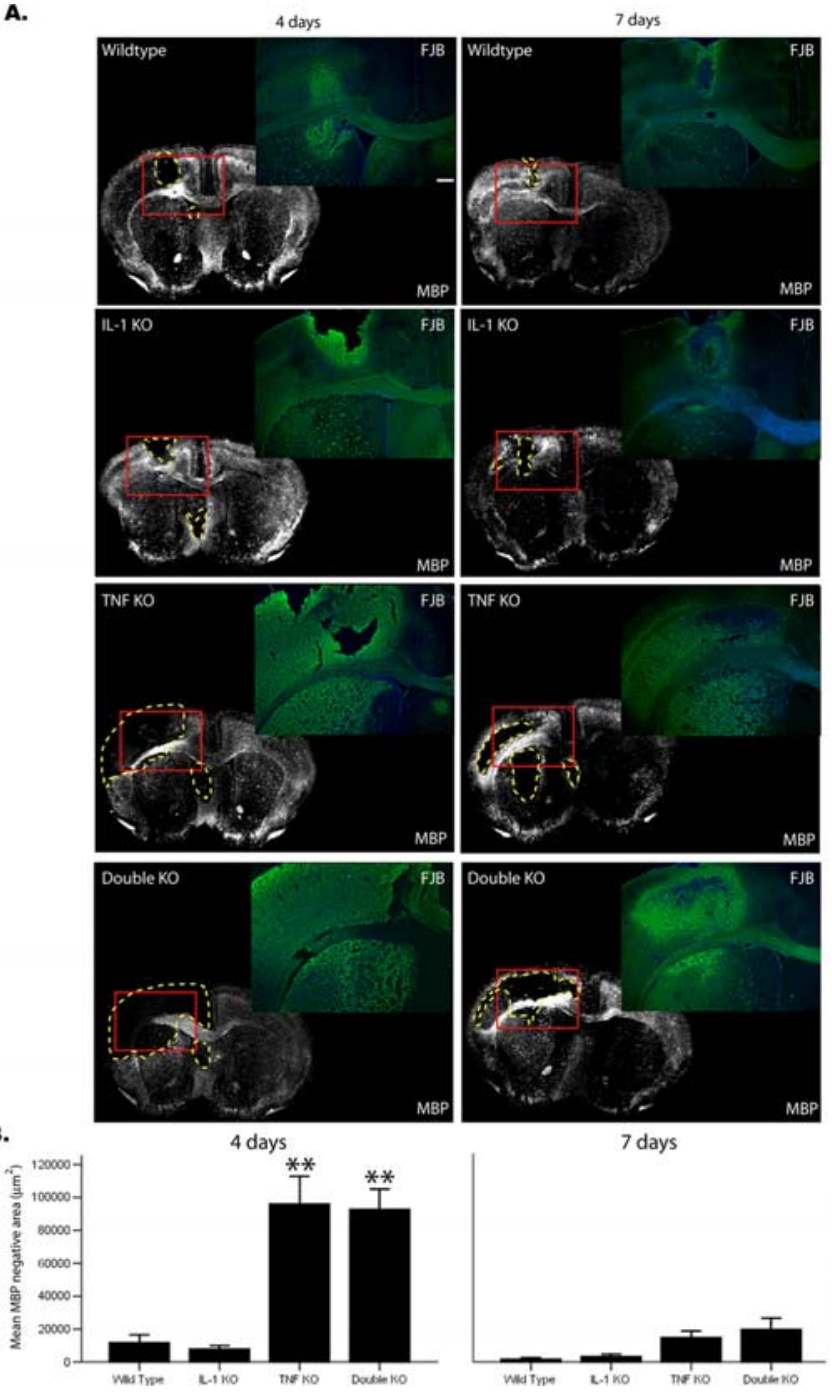

Figure 8. SNP is highly toxic for both neurons and oligodendrocytes in the brains of TNF- $\alpha$ deficient mice. Expression of MBP mRNA and FJB staining in the brains of wild-type, IL-1 $\beta$, TNF- $\alpha$, and IL-1/TNF double K0 mice 4 and $7 \mathrm{~d}$ after an intraparenchymal SNP injection. Darkfield photographs of in situ hybridization of MBP transcript were taken from brain slices dipped into NTB emulsion milk (Kodak) exposed for $10 \mathrm{~d}$. The insets show fluorescent photomicrographs from representative examples of FJB staining, used here as an index of neuronal death (green neurons). Both sections in each panel (MBP mRNA and FJB staining) come from the same mouse. Please note that whereas FJB signal increased across the hemispheres of TNF- $\alpha$ and double KO mice, MBP hybridization signal essentially vanished in the same area. A decrease in MBP gene expression levels is indicative of demyelination levels (depicted by the dashed yellow areas), which is significantly higher in TNF and double KO mice compared with the other groups of animals at time $4 \mathrm{~d}\left({ }^{* *} p<0.01\right.$; data presented as mean \pm SEM). Scale bar, $250 \mu \mathrm{m}$.

of TNF- $\alpha$ are paramount in determining the fate of neurons and myelin during NO-induced neurotoxicity.

Even if the current findings provide strong evidence for the beneficial effects of endogenously produced TNF- $\alpha$ in the brain in this model of NO-induced neurotoxicity, the mechanisms by which it exerts either its neuroprotective or neurodegenerative actions are still unclear. Of equal interest is the finding that the neuroprotective effects in the SNP model are TNF- $\alpha$ specific and do not extend to IL- $1 \beta$, another proinflammatory cytokine that is often associated with functions closely related to those of TNF- $\alpha$. It is becoming more evident that IL- $1 \beta$ and TNF- $\alpha$ serve different functions in the CNS; the injection of TNF- $\alpha$ centrally causes the specific and transient activation of the resident microglia, which is perpetuated by paracrine and autocrine mechanisms (Nadeau and Rivest, 2000), revealing what would seem to be purely neuroimmune (microglial) functions for the cytokine. However, the actions of IL- $1 \beta$, when administered centrally, seem to be greatly directed at the brain microvasculature, astrocytes, and neurons, with effects that do not abate as quickly as those of TNF- $\alpha$ (Proescholdt et al., 2002). Furthermore, it has long been established that IL- $1 \beta$ is able to signal neurons directly (Plata-Salaman and Ffrench-Mullen, 1992), which would all suggest that IL- $1 \beta$ could be most involved in the neuroendocrine, behavioral aspects of the innate immune CNS response, rather than coordinating its neuroimmune aspects. To be sure, the distinction between the actions of the two cytokines is specific to the brain, because they still act on peripheral monocytes in a similar manner. It should also be noted that the kinetics of these two cytokines in the brain is crucial in determining the fate of neurons; if administered chronically into the brain (Nadeau and Rivest, 2003), TNF- $\alpha$ is able to cause neuronal damage, and if given concomitantly with SNP, it will exacerbate the effects of the NO donor (Blais and Rivest, 2004). On the other hand, a chronic administration of IL-1 $\beta$ centrally does not cause degeneration and is able to re-establish neurotrophin activity after cortical lesions in IL- $1 \beta$-deficient mice (Herx et al., 2000). With this evidence in mind, we suggest the following conclusions: (1) the early release of TNF- $\alpha$ after an intracerebral SNP insult is essential in priming microglial cells and innate immunity to effectively and specifically resolve and phagocytose the initial excitotoxic damage caused by SNP, preventing subsequent secondary damage; (2) the absence of TNF- $\alpha$ delays activation of microglial cells, which leads to an exaggerated and nonspecific activation of microglia by the accumulation of necrotic debris, amplifying the secondary damage caused by SNP; and (3) the priming of microglial cells by innate immunity is TNF- $\alpha$ specific, because these effects do not extend to another proinflammatory cytokine, IL-1 $\beta$ (Blais and Rivest, 2004).

It is also possible that the neuroprotective effects of TNF- $\alpha$ observed in the SNP model are through activation of its different receptor subtypes. Fontaine and colleagues (2002) already suggested dual and opposite roles for TNFR1 and TNFR2 in mediating ischemic neurodegeneration. TNFR1 is believed to be associated with the detrimental effects of TNF- $\alpha$, which seem to be mostly in cases in models in which TNF- $\alpha$ production is overly stimulated (chronic TNF- $\alpha$ brain infusions, autoimmune diseases, etc.), whereas TNFR2 is associated with neuroprotective effects through an Akt/protein kinase B-dependent pathway (Fontaine et al., 2002). The importance of TNF signaling in the brain during excitotoxicity was emphasized in a study by Guo and colleagues (2004) in which they used chimeric mice in which the bone marrow-derived cells (which include infiltrating macrophage and microglia) were replaced with cells lacking both TNF- $\alpha$ receptors. These mice were found to be more vulnerable to excitotoxic damage than their nonchimeric counterparts. Furthermore, Arnett and colleagues (2001) have clearly shown the role of TNF- $\alpha$ and its type 2 receptor in proliferation of oligodendrocytes and remyelination in an acute model of demyelination, whereas others have suggested that TNF- $\alpha$ NMDA-dependent NF- $\kappa$ B activation through TNFR2 was essential to protect against glutamate-induced neurotoxicity (Marchetti et al., 2004). The importance of the neuroprotective effects of NF- $\kappa \mathrm{B}$ activation in models of Alzheimer's disease is also supported, because inhibition of NF- $\kappa \mathrm{B}$ exacerbates $\beta$-amyloid-associated apoptosis (Kaltschmidt et al., 1999). It is very likely that the beneficial effects of TNF- $\alpha$ are a combination of both its immediate actions on glial cells and more latent consequences of binding to its two 
receptors. Thus, the current results would further support the importance of a rapid, well regulated innate immune response in the brain in response to neuronal insults. Disruption of the timing (activation and resolution) and of the intensity of inflammation in the brain could have major implications in the neuropathological consequences of chronic nervous system diseases, such as multiple sclerosis, Parkinson's disease, and Alzheimer's disease. In addition, the involvement of microglial cells as the first line of defense to coordinate and mobilize cerebral immune processes is further appreciated and warrants future investigation into the processes underlying the intraglial signaling mechanisms involved in determining their neuroprotective actions in various neuropathologies.

\section{References}

Abbas AK, Lichtman AH (2003) Cellular and molecular immunology, Ed 5. Philadelphia: Saunders.

Acarin L, Gonzalez B, Castellano B (2002) Decrease of proinflammatory molecules correlates with neuroprotective effect of the fluorinated salicylate triflusal after postnatal excitotoxic damage. Stroke 33:2499-2505.

Arnett HA, Mason J, Marino M, Suzuki K, Matsushima GK, Ting JP (2001) TNF alpha promotes proliferation of oligodendrocyte progenitors and remyelination. Nat Neurosci 4:1116-1122.

Blais V, Rivest S (2004) Effects of TNF-alpha and IFN-gamma on nitric oxide-induced neurotoxicity in the mouse brain. J Immunol 172:7043-7052.

Boivin G, Coulombe Z, Rivest S (2002) Intranasal herpes simplex virus type 2 inoculation causes a profound thymidine kinase dependent cerebral inflammatory response in the mouse hindbrain. Eur J Neurosci 16:29-43.

Carlson NG, Wieggel WA, Chen J, Bacchi A, Rogers SW, Gahring LC (1999) Inflammatory cytokines IL-1 alpha, IL- 1 beta, IL-6, and TNF-alpha impart neuroprotection to an excitotoxin through distinct pathways. J Immunol 163:3963-3968.

Fontaine V, Mohand-Said S, Hanoteau N, Fuchs C, Pfizenmaier K, Eisel U (2002) Neurodegenerative and neuroprotective effects of tumor necrosis factor (TNF) in retinal ischemia: opposite roles of TNF receptor 1 and TNF receptor 2. J Neurosci 22:RC216(1-7).

Guo Z, Iyun T, Fu W, Zhang P, Mattson MP (2004) Bone marrow transplantation reveals roles for brain macrophage/microglia TNF signaling and nitric oxide production in excitotoxic neuronal death. Neuromolecular Med 5:219-234.

Herx LM, Rivest S, Yong VW (2000) Central nervous system-initiated inflammation and neurotrophism in trauma: IL-1 beta is required for the production of ciliary neurotrophic factor. J Immunol 165:2232-2239.

Kaltschmidt B, Uherek M, Wellmann H, Volk B, Kaltschmidt C (1999) Inhibition of NF-kappaB potentiates amyloid beta-mediated neuronal apoptosis. Proc Natl Acad Sci USA 96:9409-9414.

Laflamme N, Lacroix S, Rivest S (1999) An essential role of interleukin-1 $\beta$ in mediating NF- $\kappa \mathrm{B}$ activity and COX-2 transcription in cells of the blood-brain barrier in response to a systemic and localized inflammation but not during endotoxemia. J Neurosci 19:10923-10930.

Laflamme N, Echchannaoui H, Landmann R, Rivest S (2003) Cooperation between toll-like receptor 2 and 4 in the brain of mice challenged with cell wall components derived from gram-negative and gram-positive bacteria. Eur J Immunol 33:1127-1138.

Loddick SA, Rothwell NJ (1999) Mechanisms of tumor necrosis factor alpha action on neurodegeneration: interaction with insulin-like growth factor-1. Proc Natl Acad Sci USA 96:9449-9451.

Marchetti L, Klein M, Schlett K, Pfizenmaier K, Eisel UL (2004) Tumor necrosis factor (TNF)-mediated neuroprotection against glutamateinduced excitotoxicity is enhanced by $N$-methyl-D-aspartate receptor activation. Essential role of a TNF receptor 2-mediated phosphatidylinositol 3-kinase-dependent NF-kappa B pathway. J Biol Chem 279:32869-32881.

Nadeau S, Rivest S (2000) Role of microglial-derived tumor necrosis factor in mediating CD14 transcription and nuclear factor $\kappa$ B activity in the brain during endotoxemia. J Neurosci 20:3456-3468.

Nadeau S, Rivest S (2003) Glucocorticoids play a fundamental role in protecting the brain during innate immune response. J Neurosci 23:5536-5544.

Nguyen MD, Julien JP, Rivest S (2002) Innate immunity: the missing link in neuroprotection and neurodegeneration? Nat Rev Neurosci 3:216-227.

Nguyen MD, D’Aigle T, Gowing G, Julien JP, Rivest S (2004) Exacerbation of motor neuron disease by chronic stimulation of innate immunity in a mouse model of amyotrophic lateral sclerosis. J Neurosci 24:1340-1349.

Park EM, Cho BP, Volpe BT, Cruz MO, Joh TH, Cho S (2005) Ibuprofen protects ischemia-induced neuronal injury via up-regulating interleukin-1 receptor antagonist expression. Neuroscience 132:625-631.

Paxinos G, Franklin KBJ (2001) The mouse brain in stereotaxic coordinates, Ed 2. San Diego: Academic.

Perrin FE, Lacroix S, Aviles-Trigueros M, David S (2005) Involvement of monocyte chemoattractant protein-1, macrophage inflammatory protein-1alpha and interleukin-1beta in Wallerian degeneration. Brain 128:854-866.

Plata-Salaman CR, Ffrench-Mullen JM (1992) Interleukin-1 beta depresses calcium currents in CA1 hippocampal neurons at pathophysiological concentrations. Brain Res Bull 29:221-223.

Proescholdt MG, Chakravarty S, Foster JA, Foti SB, Briley EM, Herkenham M (2002) Intracerebroventricular but not intravenous interleukin-1beta induces widespread vascular-mediated leukocyte infiltration and immune signal mRNA expression followed by brain-wide glial activation. Neuroscience 112:731-749.

Soucy G, Boivin G, Labrie F, Rivest S (2005) Estradiol is required for a proper immune response to bacterial and viral pathogens in the female brain. J Immunol 174:6391-6398.

Soulet D, Rivest S (2003) Polyamines play a critical role in the control of the innate immune response in the mouse central nervous system. J Cell Biol 162:257-268.

Sun D, Newman TA, Perry VH, Weller RO (2004) Cytokine-induced enhancement of autoimmune inflammation in the brain and spinal cord: implications for multiple sclerosis. Neuropathol Appl Neurobiol 30:374-384.

Tanabe M, Matsumoto T, Shibuya K, Tateda K, Miyazaki S, Nakane A, Iwakura Y, Yamaguchi K (2005) Compensatory response of IL-1 gene knockout mice after pulmonary infection with Klebsiella pneumoniae. J Med Microbiol 54:7-13.

Turrin NP, Rivest S (2004) Innate immune reaction in response to seizures: implications for the neuropathology associated with epilepsy. Neurobiol Dis 16:321-334.

Viviani B, Bartesaghi S, Corsini E, Galli CL, Marinovich M (2004) Cytokines role in neurodegenerative events. Toxicol Lett 149:85-89.

Zheng H, Fletcher D, Kozak W, Jiang M, Hofmann KJ, Conn CA, Soszynski D, Grabiec C, Trumbauer ME, Shaw A, Kostura MJ, Stevens K, Rosen H, North RJ, Chen HY, Tocci MJ, Kluger MJ, Van der Ploeg LHT (1995) Resistance to fever induction and impaired acute-phase response in interleukin-1 beta-deficient mice. Immunity 3:9-19.

Zou JY, Crews FT (2005) TNF alpha potentiates glutamate neurotoxicity by inhibiting glutamate uptake in organotypic brain slice cultures: neuroprotection by NF kappa B inhibition. Brain Res 1034:11-24. 